\title{
STAGE INTERVENTIONS IN THE TREATMENT OF PATIENTS WITH MALIGNANT DISEASES OF THE COMMON BILE DUCT TERMINAL SEGMENT COMPLICATED BY ACUTE MECHANICAL JAUNDICE
}

\author{
Stanislav Kosulin ${ }^{1,2} \bowtie$ \\ Kharkiv Medical Academy of Postgraduate Education \\ 58 Amosova str., Kharkiv, Ukraine, 61176 \\ kosulinmd@gmail.com \\ Juriy Vinnik ${ }^{1,2}$ \\ Julia Ivanova ${ }^{1,2}$ \\ ${ }^{I}$ Government Institution «V. T. Zaycev Institute of General and Urgent Surgery \\ of National Academy of Medical Science of Ukraine» \\ 1 Balakireva entry, Kharkiv, Ukraine, 61103 \\ ${ }^{2}$ State City Hospital No. 17 \\ 195 Moskovskyi ave., Kharkiv, Ukraine, 61037
}

Corresponding author

\begin{abstract}
Obstructive mechanical jaundice is a well-researched complication of various diseases and causes, yet considering patients' condition with malignant diseases according to the stage of the malignant process, severity of complications and etc. Selection of the most appropriate method of surgical treatment is always an option where it is essential to consider finding a way between efficiency and surgical trauma.

The aim of the research is to optimize the results of surgical treatment of patients with malignant tumours of the common bile duct terminal segment complicated by acute mechanical jaundice.

Materials and methods: patients over 18 y.o. with duodenal obstruction; the presence of other active cancer pathology or blood diseases.

The research was performed on 2 different groups divided according to the use of biliary passability restoring method concluding the preferability of minimally invasive methods of bile duct decompression.

Results: minimally invasive methods are not inferior to the effectiveness of biliary decompression comparing to open methods, have a number of advantages, such as minimal invasiveness, relative safety, low incidence of complications and mortality

Conclusions: the introduction of the developed algorithm for surgical treatment of blastomatous mechanical jaundice with the consistent use of antegrade and open methods, as well as antegrade, retrograde and «rendezvous» techniques in surgically incurable patients allowed to reduce the number of early postoperative complications from $32.7 \%$ to $13.3 \%$, the number of complications requiring surgery - from $5.8 \%$ to $1.3 \%$ and the level of postoperative mortality - from $11.5 \%$ to $2.7 \%$.

Keywords: pancreaticoduodenectomy, percutaneous transhepatic cholangio-/cholecystostomy, endoscopic papillosphincterotomy, antegrade and retrograde stenting.
\end{abstract}

DOI: $10.21303 / 2504-5679.2021 .001984$

\section{Introduction}

Tumour diseases of the biliopancreatoduodenal zone (BPDZ) occupy one of the leading places among the causes of disability and mortality of the population, according to global and domestic statistics $85-90 \%$ of such cases refer to patients with a tumour causing distal biliary obstruction [1]. They compose nearly $15 \%$ of all malignant tumours of the gastrointestinal tract, which is 5-6\% among all malignant tumours diagnosed in Ukraine. Tumours of the terminal part of the common bile duct have in common a close anatomical location, frequent occurrence of obstructive 
jaundice syndrome (OJ), common clinical signs and similarity of treatment tactics $[2,3]$. The differences are associated with the prognosis of the disease and the special tactics of chosen surgical operations during early stages of the tumour process. Undoubtedly, only surgery is the only radical treatment for tumours of this localization [4]. However, due to the difficulties of early diagnosing, resectability of tumours remains extremely low: 10-15\% for cancer of the pancreatic head, 15-30\% for cancer of the extrahepatic bile ducts, $40-70 \%$ for cancer of major duodenal papilla [5]. If distant metastases or extensive local invasion are present, the method of surgical treatment as well as the frequency of complications and life expectancy do not differ significantly [6-8].

The problem of the restoration of bile adequate passage in case of common bile duct (CBD) obstruction caused by any of various malignant neoplasms of the BPDZ organs remains quite relevant at the present $[9,10]$. Surgical interventions in patients with jaundice of tumour origin are accompanied by a large number of complications, mortality can reach $15-60 \%[11,12]$. The unsatisfactory results of general surgical interventions performed in condition of the OJ dictate the need for two-stage treatment, where the first stage includes bile ducts decompression to relieve cholestasis $[13,14]$.

Due to the fact that the operability of tumours of this localization does not exceed $15-17 \%$, use of palliative general surgical methods of biliary decompression is accompanied by a high frequency of complications and mortality, determining the algorithm for performing minimally invasive bile draining operations in this category of patients is of great interest $[15,16]$.

The aim of the research was to optimizing the results of surgical treatment of patients with malignant tumours of the common bile duct terminal segment complicated by acute mechanical jaundice.

\section{Materials and methods}

The study was carried out as a clinical pattern, on the basis of the State city Hospital No. 17 (Kharkiv, Ukraine) and the «Institute of General and Emergency Surgery NAMNU of Ukraine».

Criteria for inclusion in the study: patients over the 18 y.o., OJ as main disease complication (levels of bilirubin $50 \mu \mathrm{mol} / 1$ or higher); the continuance of the OJ not exceeding the fortnight; the need of effective bile drainage; patient's agreement for complex of examination and treatment.

The exclusion criteria for the study were the following indicators: contraindications for surgical treatment (Child-Pugh type C); severe hemorrhagic disorders; acute infectious pathology (active hepatitis B and/or C); duodenal obstruction; the presence of other active cancer pathology or blood diseases; pregnancy; uncontrolled hypertension or a high-risk uncontrolled arrhythmia; mental illness, drug or alcohol addiction; patient's signed agreement for the proposed complex examination and treatment developed according WMA Declaration of Helsinki and approved by KhMAPE committee - protocol No. 14 03.07.12.

For the convenience of comparing the results and evaluating the effectiveness of the measures taken, the patients were divided into two groups depending on the way biliary passability was restored and the complex of therapeutic measures. The first group (the main group) consisted of $75(59 \%)$ patients with OJ of tumour origin, in the treatment process of which we applied minimally invasive surgical methods (from 2012 to 2019). The second group (comparisons) consisted of 59 (41\%) patients in which standard methods of treatment were applied (from 2005 to 2011). Additionally, the first group was divided into three subgroups: the first (1.1) - 40 patients with OJ as the complications of pancreatic head cancer, the second (1.2) - 23 patients with OJ, caused by the obstruction of CBD terminal part of tumour origin, third (1.3) - 12 patients with the major duodenal papilla (MDP) cancer as cause of OJ. In 59 (78.7 \%) patients of this group, minimally invasive interventions were ultimate, $16(21.3 \%)$ patients needed further operations to be performed (using laparotomic access). The second group was also divided into three subgroups, respectively, similarly according to mentioned nosology: $1^{\text {st }}$ subgroup (2.1) - 19 patients, $2^{\text {nd }}$ subgroup (2.2) 18 patients, $3^{\text {rd }}$ subgroup $(2.3)-15$ patients.

The average age of patients in group 1 was $(70.2 \pm 1.2)$ years, in group $2-(70.1 \pm 1.5)$ years. All patients were comparable in sex and age, distribution of the main and concomitant pathology and nosology, which caused the development of the OJ. 
For the selection of surgical treatment of patients we used the classification proposed by E. I. Halperin et al.

The diagnosis was verified on the basis of objective clinical examination, anamnesis, the results of clinical and biochemical analyzes, data of instrumental methods of the research. The main screening method of instrumental diagnostics was transabdominal ultrasound (TAUS), which allowed to confirm mechanical obstruction as the cause of jaundice, determining the degree of biliary hypertension, the level of biliary obstruction, identifying focal lesions of the parenchymal organs of the abdominal cavity and retroperitoneal space. The study was conducted on diagnostic devices SDU-400 (Shimadzu), Logic-500 (General Elektrics) and Aspen (Acuson).

To ensure the continual X-ray control over the manipulation, an arcoscope was used, and the latter used a mobile X-ray deck «Diasonics» (USA) with digital image processing, operating in continuous and pulsed modes with the possibility of sequential accumulation of up to 64 received images.

Bile ducts and the gallbladder punctures were performed under x-ray control with 19-22 G echotyped needles. Punctures were performed under local anesthesia (in the absence of contraindications) with a $0.5 \%$ solution of novocaine, under strictly aseptic conditions.

Endoscopic examinations were carried out on the basis of the Department of Endoscopic Diagnostic and Treatment Methods using Olimpus apparatus JF 1T-20, GIF-E, PQ-20 (Japan) and a set of endoscopic instruments. Visualization of the resulting image was achieved with a video information system of the company «Olimpus» and a DVD recorder JVC (Japan). Endoscopic retrograde cholangiopancreatography (ERPC) and endoscopic papillosphincterotomy (EPST) were performed using an Olimpus UES-10 high-frequency electric generator and a set of papillotomes.

Computer tomography (CT) was performed in order to clarify the localization, local spread of the tumour, to determine distant metastases and presence of free fluid in the abdominal cavity on a Hi Speed LX/I spiral computed tomograph (General Elcktric, USA). Magnetic resonance imaging (MRI) was performed on a Signa Contour 0.5T GJM MS apparatus from General Elektric (USA) in TI and T2 modes.

The results of surgical treatment were assessed according to the classification of D. Dindo, N. Demartines and P.-A. Clavien (2004).

Statistical data processing was performed using statistical packages MedStat v.4.1. utilising Pirson criteria.

\section{Results}

Surgical interventions performed among studied patients are shown in Table $\mathbf{1 .}$

In the comparison group, in $8(15.3 \%)$ patients, for the purpose of decompression of the gallbladder, biliodigestive anastomoses or cholecystostomies from the laparotomic approach were formed both as the first and as the main stage of surgical treatment; among that, in $36(69.2 \%)$ cases, minimally invasive (antegrade and retrograde) techniques were performed. These operations resulted in a high (62.5\%) number of postoperative complications and mortality. In the main group, biliary decompression was performed only with minimally invasive methods. Radical and conditionally radical operations as the second stage of surgical treatment were performed in $26(34.7 \%)$ patients in group 1 and in $17(32.7 \%)$ patients in group 2.

In the comparison group, as the final treatment method, pancreaticoduodenectomy (Whipple's procedure) was performed in $17(32.7 \%)$ cases, while only in $9(17.3 \%)$ cases, this operation was performed as the second stage treatment after percutaneous transhepatic cholecystostomy, which was accompanied by sufficient a high (35.3\%) incidence of postoperative complications and a mortality rate of $5.9 \%$.

Also, in the comparison group, in the most severe patients, «open» cholecystostomy and cholangiostomy (in 3 (3.8\%) patients) were performed as the final method of biliary excretion, and was also accompanied by a high (50.0\%) level of postoperative complications and a high (50.0\%) mortality due to the severity of the patients' condition. 
Table 1

Operations of choice in case of obstructive jaundice the following table is of a no need of further analysis as it counts $\%$ from total number for later comparison

\begin{tabular}{|c|c|c|c|}
\hline Treatment & $\begin{array}{l}\text { Number of pa- } \\
\text { tients (num./\%) }\end{array}$ & $\begin{array}{l}\text { Complications } \\
\text { (num./\%) }\end{array}$ & $\begin{array}{c}\text { Died } \\
\text { (num./\%) }\end{array}$ \\
\hline \multicolumn{4}{|c|}{ The group of comparison: } \\
\hline Whipple's procedure & $17(32.7 \%)$ & $5(35.3 \%)$ & $1(5.9 \%)$ \\
\hline percutaneous transhepatic cholangiostomy $\rightarrow$ Whipple's procedure & $8(15.4 \%)$ & $2(25 \%)$ & - \\
\hline «open cholecystostomy» $\rightarrow$ Whipple's procedure & $2(11.7 \%)$ & $2(100.0 \%)$ & $1(5.0 \%)$ \\
\hline ERCP, EPST, hepaticus stenting & $21(40.4 \%)$ & $3(14.3 \%)$ & $1(4.8 \%)$ \\
\hline Ry cholecystojejunostomy & $6(11.5 \%)$ & $3(50.0 \%)$ & - \\
\hline Ry hepaticojejunostomy & $2(3.8 \%)$ & $2(100.0 \%)$ & $2(100 \%)$ \\
\hline cholecystostomy, cholangiostomy & $2(3.8 \%)$ & $1(50.0 \%)$ & $1(50.0 \%)$ \\
\hline percutaneous transhepatic cholangiostomy & $7(13.4 \%)$ & $1(14.3 \%)$ & 1 \\
\hline percutaneous transhepatic cholecystostomy & $2(3.8 \%)$ & - & - \\
\hline Total: & 59 & $17(32.7 \%)$ & $6(11.5 \%)$ \\
\hline \multicolumn{4}{|l|}{ The main group: } \\
\hline Pancreaticoduodenectomy (PDR), including & $11(14.7 \%)$ & $1(9.1 \%)$ & $1(9.1 \%)$ \\
\hline Whipple's procedure & $7(9.3 \%)$ & $2(18.2 \%)$ & $1(9.1 \%)$ \\
\hline Traverso - Longmire's procedure & $2(18.2 \%)$ & $1(9.1 \%)$ & - \\
\hline percutaneous transhepatic cholecystostomy $\rightarrow$ pancreaticoduodenectomy & $10(13.3 \%)$ & $4(25.0 \%)$ & - \\
\hline Subtotal rightsided pancreatic resection & $2(2.7 \%)$ & $2(100.0)$ & - \\
\hline percutaneous transhepatic cholecystostomy $\rightarrow$ stenting & $20(26.7 \%)$ & $1(5.0 \%)$ & - \\
\hline ERCP, EPST, hepaticus stenting & $28(37.3 \%)$ & - & - \\
\hline percutaneous transhepatic cholangiostomy & $8(10.7 \%)$ & $2(25.0 \%)$ & $1(12.5 \%)$ \\
\hline percutaneous transhepatic cholecystostomy & $5(6.7 \%)$ & $1(20.0 \%)$ & - \\
\hline percutaneous transhepatic cholangiostomy + EPST «rendezvous» & $2(2.7 \%)$ & - & - \\
\hline Total: & 75 & $10(13.3 \%)$ & $2(2.7 \%)$ \\
\hline
\end{tabular}

The total number of postoperative complications in the comparison group was $32.7 \%$, and postoperative mortality was $11.5 \%$.

In the main group, biliary decompression was performed only with minimally invasive methods.

Radical and conditionally radical operations as the final stage of surgical treatment were performed in $26(34.7 \%)$ patients in group 1.

PDR as Whipple's procedure was performed in 7 (9.0\%) cases as first stage treatment and in 8 cases it was performed after the percutaneous transhepatic cholecystostomy for the CBD decompression purposes.

PDR as Traverso - Longmire's procedure was performed in 2 cases (18.2 \%), where the tumour less than $2 \mathrm{~cm}$ in diameter and was located in the uncinate process. Complications occurred in 1 case $(9.1 \%)$, eliminated by conservative treatment. At the same time, PDR in the main group was performed as the second stage surgical treatment in $4(25.0 \%)$ cases. It should be noted that D2 lymphadenectomy was an obligatory element of surgical intervention in patients of both groups with pancreatic cancer.

In general, postoperative complications after performing the PDR accounted for $9.1 \%$ of cases. 
Antegrade and retrograde stenting techniques were performed in 45 (60.0\%) patients after antegrade bile diversion and stabilization of the patient's condition.

Antegrade minimally invasive techniques as the final stage treatment were performed in $12(16.0 \%)$ of the most severe patients.

Rendezvous techniques were performed in $2(2.7 \%)$ cases in the main group; no postoperative deviations or deaths were recorded.

In general, in the main group postoperative complications occurred in 10 cases $(13.3 \%)$, mortality was $2.7 \%$.

Complications and mortality in the main group were comparable, respectively, in comparison groups calculated using Pearson criteria $\left(\chi^{2}=94.523, p=0.000\right)$.

Out of 59 patients of the 2 nd group, 3 (5.8 \%) cases of wound infection were classified as complications of the 1 st degree. Complications of the II degree were mild postoperative pancreatitis $-2(3.8 \%)$, prolonged lymphorrhea $-2(3.8 \%)$. In this group, grade IIIa complication was observed in 1 case $(1.9 \%)$ - fluid accumulation $(<10 \mathrm{~cm}$ diameter) resolved with puncture drainage under ultrasound control. Complications of IIIb degree required surgical intervention under conditions of general anesthesia. These were: pancreatoenteroanastomosis failure and erosive bleeding - 1 case $(1.9 \%), 1(1.9 \%)$ case of acute adhesive postoperative small bowel obstruction, $1(1.9 \%)$ case of eventration due to the postoperative wound infectious inflammation. The IV degree of complication included acute myocardial infarction in 4 (7.7 \%) cases, pulmonary embolism in $2(3.8 \%)$ cases Within 30 days after the operation, $6(11.5 \%)$ patients died (grade V complications). The causes of death were: 4 cases of myocardial infarction, 1 case of massive pulmonary embolism, 1 case of erosive bleeding from the pancreas stump.

Among 75 patients of the main group, 4 (5.3\%) cases of wound infection were classified as complications of the 1st degree. Complications of the II degree were prolonged lymphorrhea $2(2.7 \%)$. In the group of complications IIIa - patients with fluid accumulations $(<10 \mathrm{~cm})$ drained by puncture under local anesthesia and ultrasound navigation - 2 (2.7\%) cases. Complications IIIb degree, which required surgical intervention under general anesthesia; acute adhesive obstruction of the small intestine in $1(1.3 \%)$ case. Group IV complications included acute myocardial infarction in $2(2.7 \%)$ and pulmonary embolism in $1(1.3 \%)$ patient. Within 30 days after the operation, $2(2.7 \%)$ patients died (grade V complications). The causes of death were one case of myocardial infarction and one case of pulmonary embolism.

\section{Discussion}

Minimally invasive methods are not inferior to the effectiveness of biliary decompression comparing to open methods, have a number of advantages, such as minimal invasiveness, relative safety, low incidence of complications and mortality. [17, 18].

The choice of the method of minimally invasive biliary decompression should be determined as a tactic of choice basing on patients' condition. As the final palliative method of distal bile duct malignant strictures treatment, endoscopic retrograde prosthetics methods have certain advantages over antegrade methods of external drainage, primarily associated with preservation of the natural passage of bile in the duodenum and better adaptation by patients $[19,20]$.

Limitations of the study. Unlike isolated obstructive jaundice among otherwise healthy patients with no extra accompanying diseases and/or complications, blastomatous jaundice indicates severe BPDZ cancer cases, where jaundice is acing to a symptom, more than a direct threat. Minimally invasive interventions performed in $32(54.2 \%)$ patients in the group of comparison that in postoperative period still lead to $5(15.6 \%)$ complications and $3(9.4 \%)$ death. According to patients state and health in general, where, in some cases, first steps of minimally invasive treatment such as antegrade and retrograde drainage happen to be the final stage treatment with no more surgical interventions possible, statistical results of implemented methods differ within the framework of the research as well as the data used in referenced researches. In the main group $43(72.8 \%)$ patients received minimally invasive treatment with only $3(6.9 \%)$ complications and $1(2.3 \%)$ death.

According to this a thorough further research of case with proactive implementation of minimally invasive treatment as the first stage still need to be held. 
According to the mentioned restrictions of the research the collected complications and mortality data the research has further use both for practical application of implemented methods of minimally invasive treatment as well as theoretical statistics analysis for later comparison of upcoming if be continued researches.

\section{Conclusions}

The introduction of the developed algorithm for surgical treatment of blastomatous mechanical jaundice with the consistent use of antegrade and open methods, as well as antegrade, retrograde and «rendezvous» techniques in surgically incurable patients allowed to reduce the number of early postoperative complications from $32.7 \%$ to $13.3 \%$ The number of complications requiring surgery - from $5.8 \%$ to $1.3 \%$ ) and the level of postoperative mortality - from $11.5 \%$ to $2.7 \%$.

\section{Conflicts of interest}

The authors declare that they have no conflicts of interest.

\section{Financing}

The study was performed without financial support.

\section{References}

[1] Lupaltsov, V. Y. (2013). Sovremennoe sostoianye y perspektyvi otechestvennoi pankreatolohyy. Naukovyi Zhurnal MOZ Ukrainy, 1 (2), 37-46.

[2] Dronov, A. Y., Zemskov, S. V., Kriuchyna, E. A. (2016). Performance of total pancreatectomy for pancreatic malignancies. Klinichna khirurhiia, 10, 26-30.

[3] Giovannini, M., Caillol, F., Monges, G., Poizat, F., Lemaistre, A.-I., Pujol, B. et. al. (2016). Endoscopic ultrasound-guided needle-based confocal laser endomicroscopy in solid pancreatic masses. Endoscopy, 48 (10), 892-898. doi: http://doi.org/ 10.1055/s-0042-112573

[4] Vetshev, P. S., Kitaev, V. M., Bardakov, V. G. et. al. (2007). Klinicheskie i ekonomicheskie aspekty luchevoy diagnostiki prichin obstruktivnoy zheltukhi. Annaly khirurgicheskoy gepatologii, 12 (3), 49-50.

[5] Dudarev, I. V., Zhdanov, A. I., Dudareva, M. V. (2016). Sostoyanie vrozhdennogo i adaptivnogo pankreatita s razvernutoy kartinoy poliorgannoy nedostatochnosti. Aktualnye problemy i dostizheniya v meditsine, 34-37.

[6] Singh, S., Sachdev, A. K., Chaudhary, A. (2008). Palliative surgical bypass for unresectable periampullary carcinoma. Hepatobiliary \& Pancreatic Diseases International, 7 (3), 308-312.

[7] Kubishkyn, V. A. (2009). Periampullary tumors. Pacific Medical Journal, 2, 53-56.

[8] Budzinskiy, S. A., Shapovalyants, S. G., Fedorov, E. D., Mylnikov, A. G., Bakhtiozina, D. V. (2014). Sovremennye vozmozhnosti endoskopicheskogo retrogradnogo protezirovaniya zhelchnykh protokov v razreshenii mekhanicheskoy zheltukhi pri zlokachestvennykh opukholyakh organov pankreatobiliarnoy zony. Rossiyskiy zhurnal gastroenterologii, gepatologii, koloproktologii, 24 (5), 11-21.

[9] Nychytailo, M. Yu., Ohorodnyk, P. V., Deinychenko, A. H., Boiko, O. H., Khrystiuk, D. I., Shalkovska, H. I., Kycha, H. M. (2012). Algorithm of differential and topical diagnosis of obturationjaundice and miniinvasive correction of the main bile divertingpathways passability. Klinichna khirurhiia, 2, 5-10.

[10] Duan, F., Cui, L., Bai, Y., Li, X., Yan, J., Liu, X. (2017). Comparison of efficacy and complications of endoscopic and percutaneous biliary drainage in malignant obstructive jaundice: a systematic review and meta-analysis. Cancer Imaging, 17 (1). doi: http://doi.org/10.1186/s40644-017-0129-1

[11] Shabunin, A. V., Lebedev, S. S., Tavobilov, M. M., Bagatelia, Z. A., Grekov, D. N., Karpov, A. A., Afanasieva, V. A. (2021). Preoperative biliary drainage for malignant biliary obstruction: to drain or not to drain? And if drain, in what way? Khirurgiya. Zhurnal Im. N. I. Pirogova, (6), 101-105. doi: http://doi.org/10.17116/hirurgia2021051101

[12] Teterin, Y. S., Tigiev, L. R., Yartsev, P. A., Stepan, E. V., Rogal, M. L., Kulikov, Y. D. (2021). Management of obstructive jaundice in patients with neoplasms of the major duodenal papilla. Khirurgiya. Zhurnal Im. N.I. Pirogova, 7, 49-56. doi: http://doi.org/10.17116/hirurgia202107149

[13] Al-Taan, O. S., Stephenson, J. A., Briggs, C., Pollard, C., Metcalfe, M. S., Dennison, A. R. (2010). Laparoscopic pancreatic surgery: a review of present results and future prospects. HPB, 12 (4), 239-243. doi: http://doi.org/10.1111/j.1477-2574.2010.00168.x

[14] Chen, J., Lin, S., Zhu, Y. Y. (2016). Liver to abdominal area ratio in prognosis prediction in alcoholinduced acute-on-chronic liver failure. Zhonghua Yi Xue Za Zhi, 96 (10), 801-806. doi: http://doi.org/10.3760/cma.j.issn.0376-2491.2016.10.011 
[15] Chanchiev, Z. M. (2015). Features of acute liver failure in emergency abdominal surgery. Sovremennye problemy nauki i obrazovaniya, 6, 155.

[16] Shahrokni, A., Saif, M. (2013). Metastatic Pancreatic Cancer: The Dilemma of Quality vs. Quantity of Life. JOP. Journal of the Pancreas, 14 (4), 391-394. doi: http://doi.org/10.6092/1590-8577/1663

[17] Giovannini, M., Caillol, F., Monges, G., Poizat, F., Lemaistre, A.-I., Pujol, B. et. al. (2016). Endoscopic ultrasound-guided needle-based confocal laser endomicroscopy in solid pancreatic masses. Endoscopy, 48 (10), 892-898. doi: http://doi.org/ 10.1055/s-0042-112573

[18] Addley, J., Mitchell, R. M. (2012). Advances in the Investigation of Obstructive Jaundice. Current Gastroenterology Reports, 14 (6), 511-519. doi: http://doi.org/10.1007/s11894-012-0285-1

[19] Dougan, S. K. (2017). The Pancreatic Cancer Microenvironment. The Cancer Journal, 23 (6), 321-325. doi: http://doi.org/ 10.1097/ppo.0000000000000288

[20] Eliseev, S. M., Kornilov, N. G., Chikoteev, S. P., Gumerov, R. R. (2010). Obosnovanie khirurgicheskoy taktiki pri obturatsionnoy zheltukhe. Byul. VSNTS SO RAMN, 5 (75), 233-239.

Received date 15.06.2021

Accepted date 27.07.2021

Published date 30.07.2021
(C) The Author(s) 2021

This is an open access article under the Creative Commons CC BY license

How to cite: Kosulin, S., Vinnik, J., Ivanova, J. (2021). Stage interventions in the treatment of patients with malignant diseases of the common bile duct terminal segment complicated by acute mechanical jaundice. EUREKA: Health Sciences, 4, 34-40. doi: http://doi.org/10.21303/2504-5679.2021.001984 